\title{
LA PROTECCIÓN DE LA INVESTIGACIÓN BIOMÉDICA EN EL ESTADO SOCIAL DEL FUTURO*
}

\author{
The protection of biomedical research \\ in the Welfare State of the future
}

\author{
Juan Manuel Martín Guerrero \\ Doctorando \\ Universidad de Málaga
}

doi: http://dx.doi.org/10.18543/ed-66(1)-2018pp291-302

Recibido: 12.04.2018

Aceptado: 25.06.2018

\section{Resumen}

En la presente comunicación, que forma parte de un estudio sobre la importancia y protección que se le debe otorgar a la investigación biomédica en un futuro Estado Social, se exponen las razones fundamentales por las que debe primar el derecho fundamental a la investigación científica -art. 20.1 b Constitución Española- sobre otros intereses o bienes constitucionalmente protegidos.

\section{Palabras clave}

Investigación biomédica; estado social; derecho fundamental.

\section{Abstract}

This communication, which is part of a study on the importance and protection that biomedical research should be give in a future Welfare State, sets out the

* Cómo citar / Citation 'Chicago-Deusto' (Autor-fecha / Author-date / Lista de referencias / Reference list entries): Martín Guerrero, Juan Manuel. 2018. «La protección de la investigación biomédica en el Estado Social del futuro». Estudios de Deusto 66, n. ${ }^{\circ} 1$ : 291-302. doi: http://dx.doi.org/10.18543/ed-66(1)-2018pp291-302. 
fundamental reasons why the fundamental right to scientific research - art. $20.1 \mathrm{~b}$ Spanish Constitution - must prevail over other interests constitutionally protected.

\section{Keywords}

Biomedical research; welfare state; fundamental right.

No cabe duda, que el legislador español, desde que comenzó a regular las primeras técnicas de reproducción asistida, con la pionera Ley 35/1988 sobre técnicas de reproducción asistida, ha sido consciente de la necesidad de conciliar los bienes, valores o intereses constitucionales implicados en este tipo de técnicas, con la libertad científica e investigadora, contemplada desde 1978 en el art. 20. 1 b) de la Constitución Española, como derecho fundamental que, en el marco de un Estado Democrático de Derecho, debía ineludiblemente proyectar sus beneficios sobre la sociedad ${ }^{1}$.

No obstante, como consecuencia de la naturaleza del material objeto de investigación y/o experimentación: embriones humanos, el equilibrio entre los intereses en conflicto nunca le ha sido sencillo, entre otras, por las dificultades para delimitar las fronteras de los derechos afectados. Ya en su origen, la posibilidad de obtener embriones en el laboratorio y de investigar con ellos planteó el reto de encauzar jurídicamente esa nueva realidad biológica hasta entonces sólo protegida en el vientre materno ${ }^{2}$.

A este respecto, es conocido que la solución adoptada para determinar el alcance de la intervención sobre estos organismos consistió en otorgar un diferente tratamiento jurídico y/o nivel de protección a los embriones humanos dependiendo del estado de desarrollo biológico en el que se encontraran y de la capacidad o incapacidad de los mismos para llegar a ser personas. Así, la citada Ley 35/1988, distinguió y calificó a los embriones humanos a razón de dos periodos biológicos diferentes; Por un lado, los desarrollados in vitro desde la fecundación hasta el día catorce de vida, de los que se ocupó y a los que denominó preembriones ${ }^{3}$, y por otro, los que sobrepasaban dicha frontera

\footnotetext{
1 Ruiz La Peña 2011: 1052.

2 Lanzarote Martínez 2006: 153-154.

3 Por primera vez se utilizó en la legislación española la expresión «preembrión» como término generalmente aceptado; véase la Exposición de Motivos de la Ley 35/1988. No obstante, nunca ha existido consenso acerca de la idoneidad del famoso término acuñado por Mac Laren y popularizado por Warnock, puesto que, en general, se entiende como una categorización artificial que carece de base científica y cuyo fin ha sido amparar las intervenciones sobre el embrión en sus primeras fases de desarrollo; COMITE DE EXPERTOS SOBRE BIOÉTICA Y CLONACIÓN DE LA FUNDACIÓN CIENCIAS
} 
biológica, regulados en la Ley 42/1988, de 28 de diciembre de donación y utilización de embriones y fetos humanos o de sus células tejidos u órganos, y a los que se encargó de calificar como embriones posimplantatorios. Por su parte, respecto a la capacidad o incapacidad de los embriones para desarrollarse, la ley no la definió con precisión, sino que se limitó a enunciarla con los términos viabilidad e inviabilidad ${ }^{4}$, haciendo depender las posibilidades de investigación a que éstos tuvieran o no aquella posibilidad. Es decir, las alternativas de investigación o experimentación en España en la década de los noventa en esta materia, solo estaban referidas en las normas a los preembriones inviables, habida cuenta que la intervención sobre los preembriones in vitro viables no podía tener otros fines que los de diagnóstico o terapéuticos. Por tanto, a los embriones preimplantatorios viables y/o preembriones se les presuponía un valor o interés superior que a los calificados como inviables, de la misma forma, que a los embriones posimplantatorios y/o embriones propiamente dichos se les consideraba gradualmente más valiosos, toda vez que las posibilidades de intervención sobre los mismos se limitaban a los fines exclusivamente terapéuticos. No obstante, no se expresaban cuáles eran esos valores que preponderaban entre ambas entidades, ni los motivos que justificaban un diferente tratamiento jurídico.

Así, tanto por las expresadas presunciones ontológicas y biológicas como por el heterogéneo tratamiento jurídico que otorgaban a los embriones humanos, las leyes biomédicas de 1988, pronto fueron objeto de crítica e impugnación a través de sendos recursos de inconstitucionalidad articulados o vertebrados en torno a un motivo fundamental, como era la protección constitucionalmente exigible de la vida humana.

El Tribunal Constitucional, a este respecto, sin embargo, fue ya tajante desde la STC 212/1996, que resolvía el recurso presentado frente a la Ley 42/1988, al negar la consideración de los embriones humanos no viables siquiera como nascituri (F.J. $5^{\circ}$ ) y avalar la constitucionalidad de la Ley $42 / 1988$ por cuanto que se apoyaba en un presupuesto fundamental, como era el carácter no viable, es decir, incapaz de vivir ${ }^{5}$, de los embriones y fetos humanos objeto de donación y/o utilización.

DE LA SALUD, Informe sobre clonación. En las fronteras de la vida, Ed. Doce Calles, Madrid, 1999, p. 224; Germán Zurriaráin, 2009: 174-175.

${ }^{4}$ Quizás la única definición fue la recogida en el art. 5.3 de la Ley 42/1988. Pero como se ha dicho por algún autor: «la Ley de forma muy imprecisa, señala lo que entiende por embriones no viables: los abortados, espontáneamente o no serán considerados no viables por su grado de desarrollo a los efectos de esta Ley»; González Morán 1998: 186.

5 Posteriormente, vino a reiterar esta doctrina en la STC 116/1999, de 17 de junio, cuando en su fundamento Jurídico $9^{\circ}$, citando la Sentencia de 1996, afirmaba que: (...) aplicado «a un embrión humano, su caracterización como 'no viable' hace referencia 
Tras esta manifestación, en la STC 116/1999, si bien llegó a similar solución - la constitucionalidad de la norma recurrida- por las singularidades objeto del recurso, hubo de profundizar en los argumentos jurídicos de fondo utilizados en su primer pronunciamiento. En particular, porque ahora, los principales motivos de impugnación versaban sobre las intervenciones con fines de investigación y experimentación sobre los preembriones.

No obstante, aun la anterior tesitura, el Tribunal Constitucional no encontró obstáculo para extender la doctrina sentada en la STC 212/1996 y declarar, sin género de dudas, la constitucionalidad de los preceptos impugnados por el simple hecho de que la Ley 35/1988 sólo permitía convertir en objeto de experimentación a aquellos embriones que, por carecer de potencialidad para desarrollarse y dar lugar a un nuevo ser humano, no estaban alcanzados por la cobertura del artículo 15 de la Constitución (F.J. $\left.9^{\circ}\right)^{6}$.

A mayor profundidad, junto a esta concluyente y relevante manifestación, el Tribunal Constitucional realizó otro razonamiento, en ese momento en relación a la creación de preembriones destinados a la procreación y a la eventualidad de su crioconservación, por resultar sobrantes de las técnicas de reproducción, que supuso una vuelta de rosca en la confección jurisprudencial del estatuto jurídico del embrión preimplantatorio, que tuvo una notable incidencia en las leyes que se promulgarían posteriormente y que es verdaderamente interesante a los fines de este trabajo. En este sentido, en el Fundamento Jurídico $11^{\circ}$ de la STC 116/1999, el Tribunal Constitucional, reconoció abiertamente que ni los preembriones no implantados ni, con mayor razón, los simples gametos son, a estos efectos, «persona humana»,

concretamente a su incapacidad para desarrollarse hasta dar lugar a un ser humano, a una 'persona' en el fundamental sentido del art. 10.1 C.E. Son así, por definición, embriones o fetos humanos abortados en el sentido más profundo de la expresión, es decir, frustrados ya en lo que concierne a aquella dimensión que hace de los mismos un 'bien jurídico cuya protección encuentra en dicho precepto constitucional (art. 15 C.E.) fundamento constitucional' (STC 53/1985, fundamento jurídico $5^{\circ}$ ), por más que la dignidad de la persona pueda tener una determinada proyección en determinados aspectos de la regulación de los mismos...» (STC 212/1996, fundamento jurídico $\left.5^{\circ}\right)(\ldots)$.

${ }_{6}^{6}$ Para un análisis crítico de la citada resolución, entre otros; Cámara Águila, 1999: 125: (...) «lo que se desprende de esta sentencia es que los preceptos que regulan el tratamiento de los preembriones vivos in vitro no son inconstitucionales; pero no sabemos muy bien por qué. No queda claro si es que en esa fase del desarrollo embrionario no hay ningún principio constitucional que despliegue sus efectos, o si en cambio, resultando de aplicación, la Ley no los afecta; Bellver Capella 1999: 132: «la STC 116/1999 constituía una magnífica ocasión para que el TC hubiese definido con precisión la protección constitucional debida al embrión humano y que no se limitara a decir que la protección otorgada por la LTRA es conforme a la CE». 
por lo que el hecho de quedar a disposición de los Bancos tras el transcurso de determinado plazo de tiempo, difícilmente podía resultar contrario al derecho a la vida (art. 15 C.E.) o a la dignidad humana (art. 10.1 C.E.). Es decir, admitía expresamente que ciertos preembriones viables fueran desechados y no utilizados para la procreación al quedar inutilizados en los procedimientos de reproducción y no descartaba su preterición a favor de otros intereses de valor preferente ${ }^{7}$.

Dicho esto, los pronunciamientos del Tribunal Constitucional, junto con las conclusiones del profundo debate ético que en paralelo se había generado en la sociedad, habida cuenta la alta proporción de embriones congelados y la idoneidad de su destino ${ }^{8}$, propiciaron la reforma legal de la Ley $35 / 1988$, que llegaría, tras un intento fallido un año antes, el 21 de noviembre de 2003, con la aprobación de la Ley 45/2003. En efecto, esta norma nació con el propósito de solucionar el conflicto del destino de los preembriones sobrantes de las técnicas de fecundación in vitro (FIV), pero pronto vio frustrado su fin, toda vez que la solución parcial que ofrecía para reducir el número de preembriones congelados y para darles un destino que no fuese irremediablemente la destrucción, no satisfacía los intereses científicos, médicos y políticos que, en aquellos momentos de efervescencia en lo tocante a descubrimientos biomédicos, primaban en una sociedad que, se recordará, terminaba siglo habiendo obtenido con éxito la clonación del primer mamífero animal ${ }^{9}$ y comenzaba el siguiente descubriendo la posibilidad de aislar en el laboratorio

7 En esta línea, Romeo Malanda 2006: 129; Laurenzo Copello 2003: 113 y ss. En un sentido opuesto, sin embargo, Serrano Ruiz-Calderon 2003: 231, (...) de ello se deduce que son preembriones utilizables para reproducción que no pierden su estatus, y además, que si la técnica no requiriese o desaconsejase la crioconservación, lo que a nuestro parecer ocurre ya hoy día, no sería precisa la congelación de embriones (...).

${ }^{8}$ Para un estudio a fondo sobre el debate ético de los embriones sobrantes de las técnicas de FIV y las conclusiones alcanzadas; I INFORME ANUAL DE LA COMISIÓN NACIONAL DE REPRODUCCIÓN HUMANA ASISTIDA (CNRHA), de 1998; II INFORME ANUAL DE LA CNRHA, de 2000, sobre la investigación con embriones humanos sobrante; (...) La Comisión Nacional de Reproducción Asistida considera mayoritariamente que debe hacerse posible la investigación con embriones congelados «sobrantes» de la aplicación de técnicas de reproducción humana asistida como alternativa a su destrucción. El criterio mayoritario de la Comisión es que esa autorización debe hacerse posible mediante la modificación de las leyes que regulan en la actualidad esa cuestión y, en concreto, de la Ley 35/1988, de Reproducción Humana Asistida (...); INFORME DEL COMITÉ ASESOR DE ÉTICA PARA LA INVESTIGACIÓN CIENTÍFICA Y TECNOLÓGICA, relativo a la «Investigación sobre células troncales», de 2003.

9 Campbell KN; Mac Whir J; Ritchie, WA; Wilmut, I. 1996: 380. Y Wilmut, I, Schinieke, AE, Mc Whir, King, AJ, Campbell, KH. 1997: 810-3. 
células embrionarias humanas ${ }^{10}$ y elucubrando las posibilidades de utilizarlas con fines terapéuticos ${ }^{11}$.

Como consecuencia de este rechazo, surgió la actual Ley 14/2006, sobre Técnicas de Reproducción Asistida, que derogó finalmente la Ley 35/1988 y la Ley 43/2003, y que a diferencia de su antecesora, no limitaba el destino para investigación de los preembriones sobrantes de las técnicas de fecundación in vitro, abriendo de esa manera el campo de posibilidades de experimentación no sólo con los preembriones congelados con anterioridad a noviembre de 2003 -fecha que fijaba la Ley 43/2003- sino también a todos aquellos que resultaran sobrantes de una fecundación in vitro para fines de procreación.

Sin embargo, la verdadera relevancia jurídica de la reforma, no se encontraba en que las parejas, o las mujeres, que desde entonces se sometieran a un procedimiento de fecundación in vitro, tenían a su alcance la opción de donar los preembriones sobrantes a fines de investigación o experimentación ${ }^{12}$, o que los investigadores dispusieran de material adecuado y suficiente para sus proyectos, sino al hecho de que permitir la utilización de dichos organismos sin limitaciones temporales o biológicas implica que aquellos, en el momento de decidir sobre su destino para investigación, pueden tener capacidad de

${ }^{10}$ Este hallazgo fue compartido entre dos prestigiosos científicos y sus equipos. Thomson, James A. publicaba los resultados de su equipo el 6 de noviembre de 1998, en un artículo aparecido en la revista Science (Thomson, J.A., Itskovitz-eldor, J., Shapiro, S.S., Watnitz, M.A., Swiergiel, J. J., Marshall, V.S. y Jones, J. M., «Embryonyc stem cells lines derived from human blastocyst», Sciense, 282 (1998) 1145-7). Y GEARHART, John D., publicó los hallazgos de su grupo el mismo mes, en un artículo aparecido en la revista Proceedings of the National Academy of Sciences USA (Shamblott, M. J., Axelman, J., Wang, S.,Buug, E. M., Littlefield, J. W., Donovan, P.J. Blumenthal, P.D., Huggins, G.R. y Gearhart, J.D., «Derivation of pluripotent stem cells from cultured human primordial germ cells», Proc. Natl. Acad. Sco. USA. 95 (1998) 13726).

${ }^{11}$ La propia Exposición de Motivos de la Ley 45/2003, de 21 de noviembre, por la que se modifica la Ley 35/1988, de 22 de noviembre, sobre Técnicas de Reproducción Asistida, en su expositivo I, así lo reconoce: (...) cabe destacar especialmente los descubrimientos que se están produciendo en el ámbito de las células troncales procedentes de diferentes tipos de tejidos. Los primeros descubrimientos realizados en este campo están abriendo enormes expectativas en la investigación biomédica y farmacológica, así como en relación a su potencial terapéutico para tratar graves enfermedades que ahora son incurables (...).

12 Art. 11 de la Ley 14/2006, de 26 de mayo, sobre técnicas de reproducción humana asistida; (...) 3. Los preembriones sobrantes de la aplicación de las técnicas de fecundación in vitro que no sean transferidos a la mujer en un ciclo reproductivo podrán ser crioconservados en los bancos autorizados para ello (...) 4. Los diferentes destinos posibles que podrán darse a los preembriones crioconservados, así como, en los casos que proceda, al semen, ovocitos y tejido ovárico crioconservados, son: (...) c) La donación con fines de investigación (...). 
desarrollo o viabilidad. En definitiva, que se abriera la puerta a la investigación no sólo con embriones inviables sobrantes de las técnicas de fecundación -como hasta la fecha había sido- sino también con preembriones que, de ser transferidos a un útero materno, pueden tener las mismas posibilidades de desarrollo que aquellos que fueron utilizados en el procedimiento para cuyo fin se crearon.

En efecto, esta posibilidad, contemplada implícitamente en la citada norma, propició un debate sobre la constitucionalidad de los preceptos que la autorizan, no resuelto en la actualidad. Aunque los argumentos que se han opuesto son varios, se resumen en la tradicional infracción del deber constitucional de protección de la vida humana en todas sus fases de su desarrollo ${ }^{13}$. En este sentido, se afirma que este deber de salvaguarda de la vida humana incipiente es infringido por la Ley 14/2006, de 26 de mayo, toda vez que, al permitir la utilización de preembriones viables para fines de investigación, se está reduciendo la protección otorgada a los preembriones sobrantes de las técnicas de fecundación in vitro y los está convirtiendo en meros objetos de laboratorio. Por tanto, se contradice con la doctrina constitucional establecida al respecto, habida cuenta que cuando el Tribunal Constitucional autorizó el destino para experimentación de dichos organismos, lo hacía únicamente respecto a los no viables, no autorizando que la vida humana en sus orígenes estuviese privada de amparo jurídico alguno según la Constitución ${ }^{14}$.

A pesar de ello, y pese al clima de escepticismo o rechazo existente en parte de la comunidad científica por la efectividad práctica de los resultados obtenidos en la investigación con embriones humanos ${ }^{15}$, en el año 2007 surgió la norma con mayor incidencia y repercusión en la investigación con estos organismos, orientada a la medicina regenerativa. Así, la Ley 14/2007, de 3 de julio, de Investigación Biomédica -en adelante LIB-, además de nacer con el fin de aclarar el panorama legal, actualizando y trasladando el contenido de la obsoleta Ley 42/1988, de 28 de diciembre, en lo tocante a

13 Recordemos; STC 53/1985, de 11 de abril, F.J. Quinto: (...) la vida del nasciturus, en cuanto éste encarna un valor fundamental la vida humana garantizado en el artículo 15 de la Constitución, constituye un bien jurídico cuya protección se encuentra en dicho precepto constitucional (...); F.J. Séptimo: (...) debemos afirmar que la vida del nasciturus, de acuerdo con lo argumentado en los fundamentos jurídicos anteriores de esta Sentencia, es un bien jurídico constitucionalmente protegido por el artículo 15 de Nuestra Norma fundamental (...). Y STC 212/1996, de 19 de diciembre, F.J. Tercero y STC 116/1999, F.J. Quinto y Noveno.

${ }^{14}$ Por todos, Abellan-García Sánchez 2008: 59-83; Germán Zurriaráin 2009. A su vez, el autor cita a Serrano 2009: 209, donde afirma, a propósito de las novedades introducidas por la Ley 14/2006, que pueden ser objeto de recurso ante el Tribunal Constitucional.

${ }_{15}$ En este sentido, Moratalla 2007: 367-385. 
investigación con embriones y fetos humanos ${ }^{16}$, tuvo como objetivo principal el alcanzar conocimiento científico para aprovechar sus resultados en la salud y bienestar colectivo, ofreciendo o proporcionando un marco legal que permitiera cubrir las necesidades y demandas investigadoras de los científicos. Sin embargo, junto con ello y como contrapunto, consciente de los retos científicos a los que se enfrentaba la sociedad y de los riesgos que implica la manipulación genética, su propósito ha sido intentar conciliar aquel fin con los derechos, principios, valores o intereses que puedan verse afectados por las investigaciones realizadas sobre los seres humanos o los organismos titulares de aquellos bienes.

Precisamente, sobre esta balanza de intereses contrapuestos se ha situado una de las técnicas biomédicas que más polémica ha suscitado desde que fuera expresamente regulada en la LIB, bajo el nombre de activación de ovocitos mediante transferencia nuclear. Con esta denominación, la citada norma se ha referido al procedimiento científico consistente en trasferir el núcleo de una célula adulta a un óvulo previamente enucleado con el propósito de crear un embrión y convertirlo en fuente de células embrionarias ${ }^{17}$. Teóricamente, las bondades de este método radican en que, con las células obtenidas, dada su naturaleza regenerativa, pueden ser tratadas diversas enfermedades, que afecten al donante del núcleo celular, evitándole problemas de incompatibilidad en el trasplante. No obstante, como contrapartida, para la obtención de dichas células es imprescindible la creación y destrucción de embriones humanos, lo que genera profundas dudas sobre la moralidad y licitud de su práctica.

Aun así, el legislador, en una clara apuesta por la investigación en medicina regenerativa, en el artículo 33.2 de la LIB, permitía «la utilización de cualquier técnica de obtención de células troncales humanas con fines terapéuticos o de investigación, que no comporte la creación de un preembrión $o$ de un embrión exclusivamente con este fin, en los términos definidos en esta Ley, incluida la activación de ovocitos mediante transferencia nuclear». No obstante, lo hacía con reservas y creando una dualidad normativa errónea, habida cuenta que la norma, por una parte, permite la citada técnica («incluida la activación de ovocitos mediante transferencia nuclear»), mientras que, por otra, niega que el producto del procedimiento sea un preembrión o embrión humano («que no comporte la creación de un preembrión o de un embrión»).

16 Romeo Casabona 2007: 22-28.

17 Para conocer las características de la técnica, consultar INFORME SOBRE CLONACIÓN, «En las fronteras de la vida», elaborado por el Comité de Expertos en Bioética y Clonación del Instituto de Ciencias de la Salud de Madrid, España, 1999; Por su parte, para una conceptualización de la clonación no reproductiva, incluida la técnica de transferencia nuclear, véase; Junquera De Estéfani 2011: 355-364. 
Las razones de dicha contradicción tienen su ser, en mi opinión: primero, en una concepción ontológica equivocada del estatuto embrionario que califica al embrión humano por el hecho biológico de la fecundación y no por el de su potencialidad intrínseca para convertirse en persona; Motivo por el cual, niega a aquellas entidades que no sean producto de una fecundación entre un gameto masculino y femenino, la naturaleza de embrión humano propiamente dicho ${ }^{18}$. Y segundo, por una cuestión jurídico formal, toda vez que si permitiera la creación de embriones/activación de ovocitos mediante transferencia nuclear, bajo la premisa de que dichos entes son de la misma naturaleza que los embriones resultantes de una fecundación entre un gameto masculino y femenino, toparía con la prohibición establecida en el artículo 18.2 del Convenio Europeo de Derechos Humanos y Biomedicina de «crear embriones humanos para fines de experimentación», que la propia LIB incluye en el inciso 1 del citado artículo $33^{19}$.

Expuesto todo lo anterior, y llegado a este punto, se alcanzarían las siguientes conclusiones: 1) El legislador español, progresivamente, ha ido permitiendo mayores intervenciones sobre los embriones humanos en beneficio de la investigación científica; 2) No ha regulado un estatuto jurídico del embrión humano, ni ha conseguido identificar o definir con precisión cuáles son los valores o intereses que poseen estas entidades que los haga merecedores de la protección que luego les otorga; 3) No obstante, el límite al derecho a la investigación científica lo ha situado en aquellas intervenciones que tengan como fin exclusivo la creación de embriones humanos para dichos fines.

Por tanto, a la vista de lo expuesto, en el plano estrictamente constitucional, y bajo la premisa de que tanto el embrión creado tradicionalmente como el resultante de la técnica descrita tienen idéntica naturaleza, la pregunta

${ }_{18}$ Dicha tesis es contraria a la concepción jurídica actual del embrión humano sentada por la Sentencia del Tribunal de Justicia (Gran Sala) de 18 de octubre de 2011 (petición de decisión prejudicial planteada por Bundesgerichtshof - Alemania) - Oliver Brüstle/Greenpeace (Asunto C34/10), y por cuya consideración: «constituye un embrión humano todo óvulo humano a partir del estadio de la fecundación, todo óvulo humano no fecundado en el que se haya implantado el núcleo de una célula humana madura y todo óvulo humano no fecundado estimulado para dividirse mediante partenogénesis»; Lacadena, Juan Ramón, «Sentencia del Tribunal de Justicia de la Unión Europea sobre las patentes de células troncales embrionarias. A propósito de un informe jurídico sobre patentes: el concepto y dignidad del ser humano», Derecho y Genoma Humano, núm. 35/2011, pp. 145-180.

19 Véase, Lacadena 2007: 13-35; Abellan-García Sánchez 2008; «(...) Si se observa, la redacción de este precepto de la ley parte de un postulado ciertamente discutible, como es el descartar que el resultado de la activación de ovocitos mediante transferencia nuclear sea un embrión propiamente dicho. Y ello se hace por pura necesidad formal absoluta, ya que, en otro caso, toparía de bruces su legalidad con lo establecido en el citado Convenio sobre Derechos Humanos y Biomedicina, de 1997, ratificado por España (...). 
fundamental que se plantearía es la siguiente: ¿Contiene el embrión preimplantatorio un valor o interés constitucional digno de protección que limite el derecho fundamental a la investigación científica? o por el contrario, habida cuenta los beneficios que para la salud de las personas lleva aparejada la investigación biomédica, debe primar el derecho fundamental a la investigación científica frente a aquellos valores o intereses que puedan poseer los embriones humanos objeto de experimentación.

Analizada la jurisprudencia que sobre el inicio de la vida humana ha dictado el Tribunal Constitucional, en particular, la STC 53/1985, y las citadas SSTTCC 212/1996 y 116/1999, y aunque no se haya pronunciado expresamente sobre esta cuestión, de los razonamientos que ha ido pergeñando, en atención a los avances científicos en esta materia y a los beneficios que, previsiblemente, se obtendrán para la salud y el bienestar de las futuras generaciones, la respuesta debe ser la preponderancia del derecho fundamental. Si bien se comparte la tesis de la gradual protección el embrión desde la fecundación, ello no quiere decir que la protección otorgada al embrión preimplantatorio tenga que venir necesariamente impuesta desde la Constitución, aunque sea titular de ciertos intereses que encuentren en aquella su último fundamento. Esta tesis sería acorde con otras manifestaciones del Tribunal Constitucional en las que admite la constitucionalidad de ciertos preceptos que de facto suponen una desprotección absoluta del embrión in vitro viable, en tanto que justifican su destrucción. Así sucede claramente con la declaración de conformidad constitucional del art. 12.1 Ley de Técnicas de Reproducción Asistida, donde se admitió expresamente, desde entonces, y hasta la actualidad $^{20}$, la posibilidad de que ciertos embriones in vitro viables fueran desechados y no utilizados para la procreación -F.J. 12 116/1999_21.

En la base de tal decisión latía una clara ponderación de intereses resuelta a favor del legítimo interés de las personas con problemas de fertilidad para aprovechar los avances científicos con el fin de alcanzar la procreación, de tal manera que se justificaría de esta forma la legitimidad de aquellas prácticas en la relativización del valor de la vida embrionaria en su fase más temprana. Si esto es así, lógicamente, tampoco se encuentran obstáculos para autorizar la creación de embriones in vitro mediante fecundación tradicional o través de técnicas novedosas, como la descrita, cuyo objetivo sean la investigación orientada a mejorar las condiciones de vida de personas que padecen enfermedades incurables o extremadamente graves.

${ }^{20}$ La actual Ley 14/2006, de 26 de mayo, sobre técnicas de reproducción humana asistida, autoriza la creación de embriones para la realización de las técnicas de fecundación y permite la utilización de los sobrantes para la investigación o directamente su destrucción (art. 11.4).

${ }^{21}$ Op. Cit. Romeo Malanda 2006; Laurenzo Copello 2003 
En definitiva, a falta de un pronunciamiento expreso del Tribunal Constitucional sobre si la creación de embriones humanos con fines de experimentación - por cualquiera de las técnicas descritas- sería contraria a la Constitución, por incumplir el deber constitucional de protección de la vida humana en todas sus fases de desarrollo, de una ponderación de los intereses en conflicto, se debe concluir la primacía del derecho fundamental a la investigación científica como actividad que proyecta sus resultados sobre la salud y la dignidad de las personas aquejadas con graves enfermedades y la necesidad de que, en un estado del bienestar futuro, se cumpla con el mandato constitucional de protección de la salud, y en consecuencia, se promueva de manera efectiva la ciencia y la investigación científica y técnica en beneficio del interés general, a través de una mayor inversión económica en investigaciones biomédicas, así como con la eliminación de todas aquellas trabas legales que impidan desarrollar a nuestros científicos experimentos, cuyo fin último sea terapéutico.

\section{BIBLIOGRAFÍA}

Abellan-García SÁnCHEZ, F. «El estatuto jurídico del embrión en España: de la Ley de Reproducción de 1988 a la clonación terapéutica de nuestros días», Revista Derecho y Genoma Humano, núm. 28/2008.

Bellver Capella, V. El Tribunal Constitucional ante la Ley sobre Técnicas de Reproducción Asistida», Revista Derecho y Genoma Humano (1999).

CÁmara Águila, M. ${ }^{a}$ del P. «Sobre la constitucionalidad de la Ley de Técnicas de Reproducción Asistida: Comentario a la SRC 116/1999, de 17 de junio, Revista Derecho y Constitución, núm. 13 (1999).

Campbell KN; Mac Whir J; Ritchie, WA; Wilmut, I. «Sheep cloned by nuclear from a cultured cell line», Nature, 1996, Mar 7; 380 (6569): 64-6;

Gearhart, J. D. (Shamblott, M. J., Axelman, J., Wang, S., Buug, E. M., Littlefield, J. W., Donovan, P.J. Blumenthal, P.D., Huggins, G.R. y Gearhart, J.D.), «Derivation of pluripotent stem cells from cultured human primordial germ cells», Proc. Natl. Acad. Sco. USA. 95 (1998) 13726).

GERMÁN ZURRIARÁIN, R. «La progresiva desprotección jurídica de la vida humana en España: de la Ley 35/1988 a las leyes 14/2006 y 14/2007», Cuad. Bioét, (2009).

GonzÁlez Morán, L. «Comentario a la Sentencia del Tribunal Constitucional 212/1996 de 19 de diciembre de 1996» (Parte I), Revista Derecho y Genética, núm. 9/1998.

Informe Anual de la Comisión Nacional de Reproducción Humana Asistida (CNRHA) (1998).

INForme DEl COMITÉ ASESOR DE ÉticA PARA LA INVESTIGACIÓN CIENTÍFICA Y TECNOLÓGICA, relativo a la «Investigación sobre células troncales», (2003).

INFORME SOBRE CLONACIÓN. «En las fronteras de la vida», elaborado por el Comité de Expertos en Bioética y Clonación del Instituto de Ciencias de la Salud de (Madrid, España, 1999). 
JunQUERA DE EstéFAnI, R. «Clonación no reproductiva» (jurídico), en AA.VV. Enciclopedia de Bioderecho y Bioética, al cuidado de Carlos María Romeo Casabona, Cátedra Interuniversitaria de Derecho y Genoma Humano, Comares, Bilbao(Granada, 2011), Tomo I.

LACADENA, J. R. «La ley de investigación biomédica: algunos comentarios sobre aspectos éticos y científicos. Revista Derecho y Genoma Humano, núm. 27/2007 y «Sentencia del Tribunal de Justicia de la Unión Europea sobre las patentes de células troncales embrionarias. A propósito de un informe jurídico sobre patentes: el concepto y dignidad del ser humano», Derecho y Genoma Humano, núm. $35 / 2011$.

LanZarote Martínez, P. «La investigación y experimentación con embriones humanos: aspectos éticos y jurídicos», Cuad. Bioét. XVII, 2006/2a

LAURENZO COPELlo, P. «Clonación no reproductiva y protección jurídica del embrión: respuestas desde el ordenamiento punitivo» en AA.VV. «Jornadas: las células embrionarias y la clonación no reproductiva: un enfoque multidisciplinar» al cuidado de Alberto Omar y Gabriel bello, Universidad de la Laguna, (2003).

Moratalla, N. «¿Qué hay de nuevo sobre las células troncales? la utopía de la clonación terapéutica?; Cuadernos de Bioética, Vol. XVIII, núm. 3, (2007).

Romeo CASABona, C. «La Ley de Investigación Biomédica: pros y contras»; Revista Bioética \& Debate, Ed. Especial, núm. 50, Inst. Borja de Bioética, (2007).

Romeo MALANDA, S. «Intervenciones genéticas sobre el ser humano y derecho penal», Comares, (2006).

RuIz LA PEÑA, R. «La libertad de investigación científica», en AA.VV. Enciclopedia de Derecho y Bioética, al cuidado de Romeo Casabona, Carlos, Comares, (Granada, 2011).

Serrano Ruiz-Calderon, J. M. «Sobre la regulación de la investigación con células troncales, clonación de embriones humanos y utilización de embriones congelados sobrantes de la FIVET en España», en AA.VV. «Células Troncales Humanas: aspectos científicos, éticos y jurídicos», al cuidado de Julio L. Martínez, Descleé de Brouwer, (2003).

Thomson, J. A. (Thomson, J.A., Itskovitz-eldor, J., Shapiro, S.S., Watnitz, M.A., Swiergiel, J. J., Marshall, V.S. y Jones, J. M., «Embryonyc stem cells lines derived from human blastocyst», Sciense, 282 (1998) 1145-7).

Wilmut, I., Schinieke, AE., Mc WhiR, KInG, AJ, CAMPBELl, KH. «Viable offspring derived from fetal an adult mammalian cells». Nature, 1997, Febr. 27;385 (6619): 810-3. 